\title{
A NATUREZA DA CIÊNCIA PELAS LENTES DO CURRÍCULO: NORMATIVIDADE CURRICULAR, CONTEXTUALIZAÇÃO E OS SENTIDOS DE ENSINAR SOBRE CIÊNCIAS
}

\author{
CRISTIANO MOURA ${ }^{*}$ \\ https://orcid.org/0000-0001-7136-634X \\ TÂNIA CAMEL "** \\ https://orcid.org/0000-0002-4475-5443 \\ ANDREIA GUERRA ${ }^{1 * * *}$ \\ https://orcid.org/0000-0002-6397-3817
}

RESUMO: Pesquisas na área de Educação em Ciências apontam a importância de se ensinar sobre ciências na educação básica e na formação de professores de ciências, o que se materializa em torno do construto "Natureza da Ciência" (NdC). Apesar de reconhecer o consenso em torno ao tema, entendemos ser importante debatermos sobre o ensino de $\mathrm{NdC}$ à luz do debate sobre o porquê ensinar ciências. De forma a contribuir para esse debate, propomos nesse ensaio teórico analisar os tipos de fenômenos educacionais que as três propostas para o ensino de $\mathrm{NdC}$ mais citadas na literatura de ensino de ciências habilitam ou desabilitam. Para tal, utilizamos dois aspectos de debates sobre currículo: o da reconceptualização e seus desdobramentos para o entendimento sobre currículo e o da função prescritivanormativa de documentos curriculares. Nossa análise constata o afastamento do questionamento sobre os fins do ensino sobre as ciências nas propostas analisadas e o caráter prescritivo-normativo de todas elas.

Palavras-chave: Natureza da Ciência. Currículo. Contextualização.

NATURALEZA DE LA CIENCIA A TRAVÉS DE LAS LENTES DE LA TEORÍA CURRICULAR: NORMATIVIDAD CURRICULAR, CONTEXTUALIZACIÓN Y LOS SENTIDOS DE LA ENSEÑANZA DE LA CIENCIA

RESUMEN: Las investigaciones de la educación en ciencias han señalado la importancia de la enseñanza sobre la ciencia en la educación básica y en los cursos

\footnotetext{
* Doutorado em Ciência, Tecnologia e Educação (CEFET/RJ). Professor do Centro Federal de Educação Tecnológica Celso Suckow da Fonseca (CEFET/RJ), Rio de Janeiro, RJ, Brasil. Membro do Núcleo de Investigação em Ensino, História da Ciência e Cultura (NIEHCC). E-mail: < cristiano.moura@cefet-ri.br >

** Doutorado em História das Ciências, das Técnicas e Epistemologia (UFRJ). Professora da Fundação Oswaldo Cruz (FIOCRUZ), Rio de Janeiro, RJ, Brasil. Membro do Núcleo de Investigação em Ensino, História da Ciência e Cultura (NIEHCC).

E-mail:<tcamel@terra.com.br > .

** * Doutorado em Engenharia de Produção com ênfase em História e Filosofia da Ciência (UFRJ). Professora do

Centro Federal de Educação Tecnológica Celso Suckow da Fonseca (CEFET/RJ), Rio de Janeiro, RJ, Brasil. Membro do Núcleo de Investigação em Ensino, História da Ciência e Cultura (NIEHCC). E-mail: < andreia.guerra96@gmail.com > .
}

\footnotetext{
' Centro Federal de Educação Tecnológica Celso Suckow da Fonseca, Rio de Janeiro, RJ - Brasil.

" Fundação Oswaldo Cruz (FIOCRUZ), Rio de Janeiro, RJ - Brasil.
} 
de formación de profesores de ciencias, que se materializa en el ámbito de la "Naturaleza de la Ciencia" (NdC). Si bien se puede reconocer el consenso sobre el tema, entendemos que es importante discutir sobre la enseñanza de $\mathrm{NdC}$ a la luz de las razones por las cuales uno debería enseñar ciencias. Con el objetivo de contribuir a este debate, proponemos, en este ensayo teórico, analizar los diferentes tipos de fenómenos educativos que las tres propuestas más citadas en la literatura permiten y deshabilitan. Para esto, utilizamos dos aspectos relacionados con los debates sobre el currículo: la idea de reconceptualización y su difusión para la comprensión del currículo y también el debate sobre la función prescriptivonormativa de los documentos curriculares. Nuestro análisis encontró un alejamiento del cuestionamiento sobre los medios de enseñanza de las ciencias en las propuestas analizadas y las características normativas prescriptivas de todas ellas.

Palabras clave: Naturaleza de la ciencia. Currículo. Contextualización.

NATURE OF SCIENCE THROUGH CURRICULUM THEORY' LENSES: CURRICULAR NORMATIVITY, CONTEXTUALIZATION AND THE MEANINGS OF TEACHING ABOUT SCIENCE

ABSTRACT: Science Education researches have pointed out the importance of teaching about science in basic education and in Science teacher training courses, which materializes under the realm of the "Nature of Science" (NOS). Although one can recognize the consensus around the theme, we understand it is important to discuss about NOS teaching on the light of the reasons why one should teach science. Aiming to contribute to this debate, we propose, in this theoretical essay, to analyze the different types of educational phenomena that the three most cited proposals in the literature enable and disable. For this, we use two aspects concerning the debates about curriculum: the reconceptualization idea and their outspread for the understanding of curriculum and also the debate around the prescriptive-normative function of curricular documents. Our analysis found an estrangement from the questioning about the means of teaching about sciences in the analyzed proposals and the prescriptive-normative characteristic of all of them.

Keywords: Nature of Science. Curriculum. Contextualization. 


\section{INTRODUÇÃO}

Pesquisas na área de Educação em Ciências apontam a importância de se ensinar sobre ciências na educação básica e na formação de professores de ciências, o que se constituiu um verdadeiro consenso ao qual nos somamos (ABD-EL-KHALICK; LEDERMAN, 2000; McCOMAS, 1998, ALLCHIN, 2011, DAGHER; ERDURAN, 2014). Este consenso, se materializa em torno do construto "Natureza da Ciência" (NdC), bastante conhecido na área e que ao longo das últimas duas décadas se popularizou e tomou forma em diversos documentos curriculares ao redor do mundo. Com sua popularização, veio também seu uso como jargão. Carter (2014), no entanto, alerta que os jargões e tradições da área de ensino escondem, muitas vezes, visões ideológicas e perspectivas políticas por trás dos seus pressupostos. Isto é, é comum que se adote ou se crie uma ou outra perspectiva para o ensino de ciências, por exemplo, sem que se tenha clareza dos compromissos éticos, políticos e epistêmicos por trás de cada modelo teórico. Por vezes, o alinhamento com perspectivas já existentes é o que garante a publicação acadêmica, na medida que o trabalho passa a integrar determinada tradição dentro daquela disciplina (BAZZUL, 2014). Considerando essa falta de transparência, torna-se importante investigar os pressupostos, nem sempre claros, que estão por trás dos "modelos" existentes de $\mathrm{NdC}$. Além disso, cremos que o conhecimento sobre estes pressupostos pode ajudar a impulsionar alguns debates na área de Educação em Ciências, como por exemplo, os fins da educação em ciências ou sobre como determinadas tradições acadêmicas acabam sendo capturadas por agendas antidemocráticas que buscam eliminar a possibilidade da diferença na Educação. Outras análises vêm sendo feitas sobre modelos de NdC (ROCHA; GURGEL, 2017; HODSON; WONG, 2017; IRZIK; NOLA, 2011; ALLCHIN, 2011c; SCHWARTZ et al, 2012), muitas delas avaliando o quanto determinada perspectiva sobre $\mathrm{NdC}$ aproxima-se ou não do empreendimento científico em si. Sobre isso, nos alinhamos a Alsop e Gardner (2017) ao afirmarem que as análises a respeito de $\mathrm{NdC}$ precisam ir além do debate a respeito do quanto uma lista de características se aproxima ou não do empreendimento científico, em um sentido demarcatório. Entendemos, como esses autores, que é necessário compreender que tipo de fenômenos educacionais cada modelo teórico sobre $\mathrm{NdC}$ para a educação em ciências habilita ou desabilita, permite ou bloqueia.

Buscando uma aproximação com esse caminho, analisamos, nesse artigo, os tipos de fenômenos educacionais que as três propostas para o ensino de $\mathrm{NdC}$ mais citadas na literatura de ensino de ciências habilitam ou desabilitam, a partir dos debates sobre currículo. Essa escolha deve-se justamente ao poder de questionamento teórico que a teoria de currículo proporciona, conforme a curriculista Alice Lopes (2015a: p. 450) destaca: "A meu ver, essa é a importância do trabalho teórico. Tentar apresentar outra forma de compreender para além do que já se encontra estabilizado. É como estar sempre se perguntando: mas não poderia ser de outro modo?’. Historicamente, o campo do currículo compreendeu determinados debates que, se a princípio parecem superados no campo curricular, deixaram rastros de seus registros de forma a se fazerem presentes em propostas 
educacionais contemporâneas (LOPES; MACEDO, 2011). Buscamos mostrar com este trabalho que isso também é verdade para o caso de $\mathrm{NdC}$.

Ainda no campo curricular, é latente o debate sobre o papel normativo da teoria de currículo. De forma simplificada podemos dividir o debate em duas grandes vertentes. De um lado há os que defendem a importância de se construir mecanismos que garantam que estudantes de diferentes classes sociais terão uma base curricular comum. De tal forma, que os estudantes de classe menos privilegiada possam ter as ferramentas necessárias para entender o mundo e nele atuar criticamente. Do outro encontram-se os críticos da normatividade curricular. A principal crítica desse grupo refere-se ao fato de que a criação de um currículo único, e, portanto, a normatividade contribuem para a construção de testes avaliativos de caráter nacional e global, que estimulam competição e meritocracia. Considerando que o constructo $\mathrm{NdC}$ se faz presente em muitos documentos educacionais, tomaremos a questão da normatividade como lente para entender a constituição do campo de pesquisa sobre $\mathrm{NdC}$ no que diz respeito a seus aspectos normativos ou não-normativos, sob um ponto de vista curricular.

Em síntese, neste ensaio teórico, defendemos, a partir dos estudos sobre currículo, que os principais modelos de $\mathrm{NdC}$ presentes na literatura internacional encaminham para visões de educação que possuem tendências normativas, e, portanto homogeneizantes, que expulsam a diferença do currículo, que reificam o conteúdo e que restringem o entendimento do que vem a ser contextualização.

Ao se situar no campo do ensaio teórico, o estudo aqui apresentado, conforme síntese de características em definições de diversos autores pesquisados por Pena (2005), consiste de um estudo formal, discursivo, caracterizado por exposição crítica, lógico-reflexiva e argumentação rigorosa de alto nível de interpretação do autor, que possui o intuito de defender determinada tese. Ainda sobre o gênero ensaio teórico, Larrosa (2003) assinala seu caráter "impuro", que coloca fronteiras em questão. No exemplo analisado por Larrosa, as fronteiras entre filosofia e literatura são postas em questão. No presente ensaio, há um híbrido que se move entre o ensino de ciências e a educação, no que diz respeito a tradições disciplinares. Outras características defendidas por Larrosa (2003) para o gênero ensaio também estão aqui presentes: sua ligação com o tempo presente (que surge ao analisarmos modelos de $\mathrm{NdC}$ contemporâneos), a não-pretensão de construir sistemas de totalidade, a adoção da escrita como meio de trabalho, como problema, o que contribui, inclusive, para converter o método em problema, não mantendo-o como "dado".

Para defender a tese enunciada, iniciamos com um apanhado sobre algumas ideias da teoria de currículo, centrando principalmente em dois debates. O primeiro refere-se ao movimento curricular dos anos 1970 conhecido como reconceptualização e seus desdobramentos para o entendimento sobre currículo. O segundo debate foca a temática da normatividade curricular, isto é, a discussão sobre a função prescritiva-normativa de documentos curriculares. Após isso, selecionamos os três modelos mais citados de $\mathrm{NdC}$ na literatura para, entendendoos como documentos curriculares, analisá-los à luz dos aspectos mobilizados na primeira seção. Ao final, concluímos com algumas considerações e traçamos consequências para a área de Educação em Ciências. 


\section{TEORIAS DE CURRÍCULO: ARTICULANDO LENTES PARA ENXERGAR A NATUREZA DA CIÊNCIA COMO MOVIMENTO CURRICULAR}

O entendimento do que é currículo está em constante disputa na literatura educacional. Lopes e Macedo (2011) apontam que o currículo escolar como conhecemos hoje tem parte de suas origens na América do Norte, baseado em princípios eficientistas de uma sociedade em franca industrialização. Nesse contexto, em 1918, Franklin Bobbitt propõe um currículo cuja função primordial é a preparação de jovens para uma vida economicamente ativa. Nesse modelo de organização curricular, valorizavam-se os componentes particulares da atividade de bons profissionais.

Esta perspectiva eficientista se aprofundou na proposta de Ralph Tyler, em 1949. Para Tyler, a organização e desenvolvimento do currículo deve buscar responder as seguintes questões básicas: quais objetivos educacionais que se pretende atingir; quais as experiências educacionais que podem ser oferecidas e que tenham probabilidade de levar ao alcance do que se pretende atingir; como organizar de forma eficiente essas experiências; e, por último, como ter certeza de que esses objetivos foram alcançados, ou seja, como avaliar (SILVA, 2015). Nesse caminho, Tyler entende que a decisão sobre quais objetivos a escola buscaria alcançar deve se apoiar nos estudos sobre os estudantes, sobre a vida contemporânea fora da educação e na opinião dos especialistas sobre a organização do conhecimento.

Tyler conferia à fase de definição dos objetivos uma importância capital no processo de design do currículo. Para ele: "se formos estudar um programa educacional sistemática e inteligentemente devemos primeiro ter absoluta segurança quanto aos objetivos educacionais a serem atingidos" (TYLER apud KLIERBARD, 2011). A proposta de Tyler possui vários pontos de continuidade com a proposta de Bobbitt, ao adotar princípios eficientistas com consequências desde a definição dos objetivos educativos até as formas de avaliação (KLIEBARD, 2011). Tyler propõe que a avaliação, a última etapa do processo educativo, seja capaz de determinar em que medida os objetivos educacionais foram alcançados pelo programa de ensino. Ou seja, a enunciação de objetivos não serve apenas à seleção e organização das experiências que comporão o currículo, mas também como uma matriz de referência, um padrão, a respeito do qual as expectativas iniciais são avaliadas (KLIEBARD, 2011).

Embora na primeira metade do século XX surjam outras perspectivas como o progressivismo de John Dewey, voltada à diminuição das desigualdades sociais geradas pela sociedade urbana industrial (LOPES; MACEDO, 2011), é a chamada racionalidade tyleriana, com sua perspectiva linear e prescritiva de instrução que dominou o campo do currículo até o início da década de 1970. Isso ocorre porque essa racionalidade torna-se um poderoso instrumento capaz de orientar e definir práticas curriculares de uma maneira simples, estruturada e organizada. A tarefa da teoria curricular para Ralph Tyler era elaborar uma perspectiva capaz de relacionar todos os fatores envolvidos no desenvolvimento de um programa educacional, isto é, objetivos, conteúdos, métodos, organização e avaliação. Esta seria uma teoria do processo de desenvolvimento curricular, apolítica, administrativa e calcada numa base técnica (PACHECO, 2000). 
No final da década de 1970, com o movimento de reconceptualização curricular, a racionalidade tyleriana passou a ser contestada. Pacheco (2000) afirma que esse movimento não possui um eixo único de atuação, isso é, não é um movimento homogêneo, mas se caracteriza fundamentalmente por ir contra a perspectiva tecnicista, que nega as vozes dos professores e estudantes no processo de construção curricular. O movimento de reconceptualização abarca, assim, uma compreensão crítica do campo, entendendo "crítica" aqui num sentido de oposição ao que estava posto (SILVA, 2015). Inicialmente, esse movimento de reconceptualização pretendia abarcar tanto as críticas de viés fenomenológico, quanto as de viés mais marxista e estrutural. Porém estas últimas rejeitaram o rótulo reconceptualista por virem esse movimento muito centrado em questões subjetivas e, supostamente, pouco políticas (idem).

Embora os entendimentos a respeito do currículo tenham mudado ao longo do tempo e principalmente após a reconceptualização, a tradição da racionalidade tyleriana se constituiu de tal feita hegemônica em certo momento, que é possível encontrar até hoje fragmentos de sua racionalidade em propostas curriculares (LOPES; MACEDO, 2011). Com estes fragmentos transladam-se, também, as consequências do entendimento do currículo a partir dessa óptica exclusivamente administrativa, como classificam alguns autores. Uma dessas consequências é a criação de um vínculo estreito entre currículo e avaliação, na medida que uma parte importante dessa racionalidade se volta a avaliar a própria proposta curricular a partir do alcance dos objetivos desenhados previamente na etapa de proposição do currículo. Fragmentos da racionalidade tyleriana também são identificados na linguagem utilizada para falar de currículo. Expressões como "design curricular", por exemplo, remetem a essa tendência mais administrativa da perspectiva teórica de Ralph Tyler.

Um ponto importante a se destacar é que desde a reconceptualização, com a ampliação dos entendimentos sobre currículo e suas consequências, alguns debates passaram a emergir de maneira mais evidente. Se o currículo não se restringe a determinar uma lista de conteúdos ou mesmo uma lista de comportamentos que a escola deve transmitir, mas se relaciona com poder, ideologia, reprodução de comportamentos sociais e as histórias de vida dos estudantes, qual deve ser, então, o papel da teoria curricular? É este um papel prescritivo-normativo ou apenas de crítica ao que existe? É nesse contexto em que se inscreve o debate sobre a normatividade curricular, que exploramos a seguir.

\section{Normatividade Curricular}

As discussões sobre normatividade curricular são, em alguma medida, uma metonímia do debate maior sobre a que serve a teoria curricular. Young (2014) discute a relação entre as produções acadêmicas da área de currículo e as diversas reformas curriculares a que assistimos no mundo, destacando que as primeiras parecem ausentes das reformas. Dando o exemplo do seu país, Young afirma que "é perturbador que a voz da teoria do currículo quase não seja ouvida [nessas reformas]" (p. 195). Segundo ele, isso ocorre porque o papel crítico tem se sobressaído ao papel normativo na teoria de currículo. Para ele, a teoria de currículo deveria ter um papel crítico de analisar as propostas curriculares e apontar os pontos 
fortes e fracos destas, e, também, um papel normativo de propor normas, regras, que orientem a elaboração e a prática do currículo. Para Young (2014), a visão normativa do currículo "se torna uma fonte de tecnicismo - dizer aos professores o que fazer - se estiver separada de seu papel crítico” (p. 194), enquanto que é difícil encontrar um propósito às críticas que estão separadas de suas implicações normativas, isto é, a crítica pela crítica. Young (2014) afirma que esse desequilíbrio entre as funções crítica e normativa é produto de um movimento histórico que as separou, levando muitas vezes a uma crítica sem proposição de alternativas. Para ele, as proposições não precisam se concretizar em uma lista completa do que fazer, mas devem ao menos produzir algumas orientações, que permitam ir além da crítica pura e simples. Michael Young não é único em defender essa posição. Moreira (2013), seguindo argumentos de Michael Apple, lamenta que o campo do currículo venha negligenciando a preocupação "com o ensino, com o currículo, com a forma e o conteúdo do conhecimento escolar, com os sujeitos implicados no processo".

Esta preocupação de Moreira e Young é também cara a outros autores, conforme analisam Lopes e Borges (2017), representando, assim, um movimento que advoga a centralidade do conhecimento na discussão curricular, defendendo um currículo como um conjunto de conhecimentos mínimos a seres ensinados/ aprendidos. Conforme Young (2014, p. 192), trata-se de responder à questão "o que todos os alunos deveriam saber ao deixar a escola?". Isto porque, para estes teóricos, ao abarcar diversas novas teorias oriundas das ciências humanas e sociais (em especial em vertentes pós-estruturais), a teoria de currículo teria perdido o foco. O movimento de crítica ao pós-estruturalismo afirma que a discussão do currículo como fenômeno discursivo tem esvaziado o debate acerca dos conhecimentos constituídos historicamente, sobre como ensiná-los e aprendê-los, organizá-los e selecioná-los, em favor de uma discussão que não tem sido frutífera, na medida que é menos normativa do que se defende que deveria ser.

Por sua vez, os curriculistas de matriz pós-estrutural têm (re)afirmado um currículo sem fundamentos (LOPES, 2015a), isto é, um currículo onde perde força a prescrição e ganha força a indecidibilidade, o plural e o heterogêneo. Isso significa se contrapor a tendências homogeneizantes, como a proposta de textos curriculares comuns como a BNCC (Base Nacional Comum Curricular). Para Lopes (2015a), a tentativa de fixar o mínimo que os estudantes devem aprender tende a operar com uma ideia de conhecimento reificado, algo a ser transmitido. E, dessa forma, afasta-se de um conhecimento como produção cultural sempre traduzida e conectada às experiências dos sujeitos envolvidos na performance curricular. $\mathrm{Na}$ medida em que se aproxima de um conhecimento reificado, a tendência, segundo Lopes (2015a), é entender o conhecimento como passível de ser apropriado (em uma lógica de transmissão), medido, listado e aplicado, tornando-se um caminho de acomodação das lógicas que permitem e promovem a atuação dos exames internacionais como PISA e TIMSS, com todas as críticas já endereçadas a esses modelos do ponto de vista da teoria curricular (POPKEWITZ, 2013). ${ }^{1}$

Lopes (2015b) defende, baseada na teoria de discurso de Laclau, que "não existem duas ordens no mundo, uma normativa e outra descritiva" (p.123), e que, portanto, essa separação de papéis postulada por Young não seria uma boa descrição para a produção curricular. Continua Lopes (2015b): "Tais dimensões [a normativa 
e a descritiva] se interpenetram, pois não existem fatos sem significação, descrição sem valores" (p. 123). Discordando da premissa de Young de que haveria algo que pode ser classificado como o "melhor conhecimento" e que este deveria figurar no currículo, Lopes (2015b) aponta que como todo conhecimento é contextual e produzido a partir de contingências, esse objetivismo pretendido é ilusório. Para Lopes (2015a), aplicando essa lógica à produção curricular, a tarefa para este campo teórico é identificar o que as diferentes visões possibilitam e viabilizam e o que elas bloqueiam, em vez de se ater a uma função crítico-normativa. Não há que se atuar para preencher o déficit normativo das defesas curriculares de matriz póscrítica, mas apostar nesse "déficit" - classificado por Lopes (2015a) como vazio normativo em vez de déficit (pela impossibilidade de plenitude) - como sendo algo produtivo do ponto de vista político.

A preocupação de Young (2014) quando defende uma teoria de currículo mais "pragmática" é compreensível se considerarmos os diversos exemplos brasileiros e internacionais, nos quais reformas curriculares têm se sucedido com baixa participação da comunidade educacional e com resultados questionáveis. Por outro lado, os argumentos de Lopes (2015a; 2015b) são bastante convincentes sobre a inadequação de pensar o currículo com a pretensão de cumprir um papel normativo no sentido que Young propõe. Dessa forma, propomos olhar para este debate em termos análogos à postura que temos encarado a História das Ciências como campo de conhecimento a partir da ótica da História Cultural das Ciências, isto é, buscando algo para além do discurso. Conforme Pimentel (2010) coloca, a História Cultural das Ciências, imbuída de seu olhar para a ciência a partir das práticas, passa a observar não apenas os textos produzidos historicamente pelos cientistas, mas também seus feitos.

Isso significa dizer que talvez não seja tão importante definir qual posição neste debate é a mais acurada do ponto de vista da representação do que é o currículo. ${ }^{2}$ Algo mais fundamental seria entender quais os efeitos práticos destes textos nos diversos contextos educacionais ao se adotar uma perspectiva de currículo desta ou daquela forma em termos de sua normatividade. Nesse sentido, torna-se importante a ressalva de Lopes (2015a), endossada por Popkewitz (2013), de que os processos de estabilização curricular, definição de normas, documentos curriculares mínimos e centralizadores (como é o caso da BNCC) atuam muitas vezes como facilitadores da estandardização que, por sua vez, concorre para a atuação de mecanismos componentes da cultura da testagem. Esta, em linhas gerais e conforme abordado por Miller (2014), consiste na padronização excessiva dos currículos, dos programas de formação docente, de testes de larga escala que procuram aprisionar a educação dentro de um modelo único e previsível de produção de subjetividades, de onde se expulsa as diferenças, o imprevisível e possibilidades diversas à metrificação na educação. Outros efeitos da norma, conforme explorado por Popkewitz (2013) para o caso dos exames de larga escala e por Macedo (2017), dizem respeito à expulsão da produção da diferença nos currículos e também daquilo que não pode ser controlado. Tudo isso, que parece ser um debate eminentemente teórico e abstrato, reafirma que a insistência no papel normativo da teoria de currículo tem como efeitos práticos a produção do mesmo, ou seja, a formação de cidadãos para se encaixar no que já existe. 
O debate sobre normatividade é fundamental para a teoria curricular, na medida que mobiliza discussões entre correntes teóricas que são centrais em vários temas diferentes no campo do currículo. Os pós-estruturalistas trazem outras questões a serem consideradas, quando destacam que, pela óptica do discurso, uma crítica curricular ao que existe, além de ajudar a criar consensos dentro da área, que permitem caminhar em determinadas direções e não em outras (o que não necessariamente representa o estabelecimento de uma norma), proporciona um movimento "sem fim de pensar, imaginar, propor, reconsiderar, reinterpretar e rever várias concepções situadas e contingentes de currículo e suas óbvias e invariavelmente imbricadas relações com ensino e aprendizagem" (MILLER, 2014, p. 2045). Ou ainda, segundo Lopes (2015a), ao falar do trabalho teórico: "Não se trata de assumir uma posição como certa ou errada [...], mas tentar entender o que uma dada perspectiva viabiliza e o que bloqueia [...]” (p. 450)

Essa desconfiança perene, este olhar analítico que discute interesses por trás das reformas curriculares, é o que talvez constranja determinados avanços do capital nos temas da educação. Embora não estejam engajados diretamente neste debate, entendemos que é desse sentido mais analítico que normativo que Bazzul (2014) e Carter (2014) falam quando afirmam a importância de se investigar os discursos que sustentam práticas da educação em ciências e da pesquisa em educação em ciências, seus jargões, siglas e tradições. Quando Young (2014) afirma que vê com maus olhos o fato de a voz dos curriculistas não ser ouvida em processos de reforma curricular, isso se deve menos ao fato de estes não produzirem pesquisas de cunho mais normativo e mais a outros interesses envolvidos. Ao propor restringir o campo do currículo a determinada forma de produção de significação, Young (2014) minimiza o jogo político que está implicado na produção de pesquisas, sejam elas dentro do campo do currículo ou não. Dicotomizando artificialmente a questão - tendo em vista o argumento de Lopes (2015a) que liga inextrincavelmente as funções crítica e normativa para a teoria curricular - podemos perguntar: deveria o campo do currículo abster-se da crítica (ou torná-la subsidiária ao papel normativo) e adotar um viés normativo para ajudar a construir documentos como a BNCC, por exemplo, ou segue sendo importante apontar esses movimentos da geopolítica educacional para que se coloque em pauta os interesses que estão por trás das reformas propostas? Cabe lembrar ainda que optando pelo segundo caminho, ainda assim, segundo Lopes (2015b), estariam sendo produzidos elementos que ajudariam a construir propostas curriculares.

Tomando como base a discussão sobre normatividade e o breve histórico das transformações pelas quais passou a teoria curricular, passamos agora à análise de alguns pressupostos que podem ser identificados em uma leitura de propostas encontradas na literatura sobre $\mathrm{NdC}$.

\section{Natureza da ciência segundo a teoria curricular}

Dada a extensão do debate sobre $\mathrm{NdC}$ na literatura de educação em ciências, para uma análise produtiva que leve em consideração diversos aspectos da composição dos textos curriculares que analisamos a seguir, é necessário restringir a análise a uma 
quantidade razoável a ser abordada na extensão desse artigo e que, ao mesmo tempo, seja capaz de apontar questões importantes à questão investigada nesse texto.

Para isso, antes é importante esclarecer o que estamos classificando como "modelos" de NdC. Essencialmente, entendemos tais modelos como proposições presentes na literatura de educação em ciências que constituem um todo coerente, que possuem uma proposta de como poderia ser implementado a temática na prática pedagógica. Com base nisso e para garantir a relevância de nossa análise, utilizamos o resultado do trabalho de Amador-Rodríguez e AdurizBravo (2017), quando apontam que na literatura as duas concepções construídas após o estabelecimento da $\mathrm{VC}$ de $\mathrm{NdC}$ mais citadas, para além da visão consensual (VC) - que apresentamos na sessão seguinte - são as propostas de Douglas Allchin (2011c) e de Gurol Irzik/Robert Nola (2011). Além dessas propostas, analisamos também o modelo de $\mathrm{NdC}$ mais citado, que é a $\mathrm{VC}$, representada por um conjunto de publicações de Norman Lederman e outros autores (McCOMAS, 1998; McCOMAS, 2008; OSBORNE et al, 2003; LEDERMAN et al, 1998; LEDERMAN et al, 2002; ABD-EL-KHALICK; LEDERMAN, 2000). Cumpre destacar que tanto a proposição de Allchin (2011c) quanto a proposição de Irzik e Nola (2011) já geraram publicações que avaliam a implementação em sala de aula dessas propostas como Santos (2018), que utiliza a proposta de Allchin, e o modelo Family Resemblance Approach (Abordagem da Semelhança de Famílias) (DAGHER; ERDURAN, 2014), que tem gerado diversas implementações em diferentes níveis educacionais, a partir da proposta de Irzik e Nola (2011). A respeito da VC, é desnecessário apontar a sua ampla penetração na área, já que seus artigos sobre $\mathrm{NdC}$ estão entre os mais citados no que se refere ao tema $\mathrm{NdC}$ e seus instrumentos de avaliação já foram traduzidos em diversas línguas, inclusive o português (EL HANI et al, 2004), e usados em diversos países. Motivados por essas considerações, descrevemos os três modelos de $\mathrm{NdC}$ selecionados e realizamos uma análise à luz dos aspectos levantados na discussão sobre teoria curricular.

\section{A visão consensual}

O modelo teórico mais conhecido sobre $\mathrm{NdC}$, a $\mathrm{VC}$, consiste numa lista de afirmações (tenets) ${ }^{3}$ sobre a natureza do conhecimento científico que são de consenso entre especialistas de diferentes áreas (filosofia, sociologia, história, educação, psicologia) sobre as principais características do empreendimento científico, apesar de esses especialistas não estarem de acordo quando se pretende que definam a natureza do conhecimento científico. Por ser uma lista consensual é considerada um guia orientador para que o professor possa explorar a dimensão metacientífica e epistemológica da construção da ciência (LEDERMAN et al, 2002; MCCOMAS, 2008; OSBORNE et al, 2003). Este modelo teórico inspirou a criação de diversos testes padronizados destinados a avaliar em pequena e larga escala concepções de NdC (VNOS, VOSTS, COCTS etc.), que ficaram amplamente conhecidos e foram utilizados em muitos trabalhos na área.

Rememorando a trajetória de construção dessa perspectiva sobre $\mathrm{NdC}$, Hodson e Wong (2017) apontam que a geração de um consenso com itens para 
descrever a ciência começa a se tornar mais clara por volta dos anos 2000. McComas e Olson (1998) fazem, em 1998, uma pesquisa em documentos curriculares de países de língua inglesa (Estados Unidos, Canadá, Austrália, Inglaterra/País de Gales e Nova Zelândia), concluindo que nos currículos, que já fazem menção ao ensino sobre a ciência nas escolas, há uma sobreposição considerável em certos elementos de $\mathrm{NdC}$. Estas características foram definidas, então, pelos autores dentro de quatro categorias: História das Ciências, Filosofia da Ciência, Sociologia da Ciência e Psicologia. Com base nisso, são apontadas 30 afirmações sobre a ciência que podem ser identificadas em ao menos um dos currículos analisados. Dessas afirmações, as catorze ideias que aparecem em um maior número de currículos são selecionadas e transformadas numa lista consensual sobre a ciência (MCCOMAS; CLOUGH; ALMAZROA, 1998)

McComas e Olson (1998) reconhecem a falta de consenso na filosofia da ciência sobre o que é a ciência e sobre como ela funciona, porém destacam que é possível encontrar pontos de concordância sobre isso para fins didáticos. Esses pontos de concordância sintetizados na lista consensual serviriam para estabilizar um conhecimento de $\mathrm{NdC}$ destinado à educação básica, já que neste nível de ensino discussões mais complexas sobre a ciência seriam infrutíferas.

Alguns anos mais tarde, Osborne e colaboradores (2003), a partir de um estudo com a comunidade especializada (25 experts), apontaram para uma concordância razoável com os aspectos levantados por McComas, Clough e Almazroa (1998) e discordância com Alters (1997a). Este último, após estudos realizados também com participação de especialistas (com 187 questionários respondidos por especialistas) chegou à conclusão de que não havia nem mesmo um consenso mínimo entre os cientistas. ${ }^{4}$

As tentativas de geração de um consenso sobre $\mathrm{NdC}$, porém, datam de estudos mais antigos. Também de Alters (1997a), observamos que aquelas que talvez tenham sido as primeiras listas de consenso sobre $\mathrm{NdC}$ foram geradas ainda na década de 1980, em 1983 com a tese de doutoramento de Norman Lederman (1983 apud ALTERS, 1997a), com os estudos de Giddings (1982 apud ALTERS, 1997a). Essa lista consensual aos poucos foi mobilizada para compor documentos curriculares. Sobre isso, Alters (1997a) aponta que em 1993 o Projeto 2061 da AAAS já apresentava em seu texto uma lista de princípios baseados em aspectos de $\mathrm{NdC}$ que os estudantes deveriam saber, marcando, assim, a adoção de uma lista consensual num documento educacional.

Em 2002, em artigo que hoje conta com quase 2000 citações, Lederman et al (2002) fazem a proposta do questionário VNOS, posteriormente dividido nos formatos A, B e C. Esta proposta, como denota seu grande número de citações, foi amplamente utilizada na área de Educação em Ciências para gerar avaliações das concepções sobre NdC. ${ }^{5}$ El-Hani, Tavares e Rocha (2004) apresentaram uma versão em português de tal material. O uso de questionários de avaliação para concepções de NdC, como apontam Lederman, Wade e Bell (1998), no entanto, não é exclusivo dos instrumentos citados, constituindo-se numa tradição que vem desde 1954. Até o ano de 1995 havia 24 proposições de materiais de avaliação de concepções de $\mathrm{NdC}$. Apesar disso, os documentos que surgem a partir da década de 
1990 se diferenciam dos primeiros por estarem associados a listas de características sobre a ciência mais ou menos estáveis. ${ }^{6}$ Isto é, representam o estabelecimento de uma norma que passa a ser replicada na comunidade de Educação em Ciências.

Cabe notar que seus proponentes e defensores parecem constituir um "bloco" de pesquisadores, conforme pode ser notado no artigo coletivo de Smith et al (1997) de respostas às críticas de Alters (1997a).7 Além disso, a lista consensual muda, ainda, algumas vezes ao longo dos anos 2000, como pode ser notado nas publicações mais recentes. Em 2008, William McComas não apenas reafirma o consenso declarando que pesquisas diferentes "surpreendentemente sugeriram conjuntos paralelos de objetivos para o ensino de $\mathrm{NdC}$ na educação básica" (McCOMAS, 2008, p. 250), como amplia o conjunto de princípios (tenets), a partir de sua pesquisa realizada em 2005 com livros populares de divulgação científica ("para leitores gerais"), que mostra "alto nível de correlação" com listas sugeridas por outros pesquisadores. A evidenciação dos mecanismos de atuação interna para formação da chamada lista consensual poderia gerar uma pesquisa à parte.

Podemos, assim, sintetizar algumas características da lista consensual. Ela é uma proposta que nasce em um contexto de questionamento ao ensino de ciências pelo fato de este se dedicar mais aos "fatos, hipóteses e teorias da ciência - o 'que' da ciência - mas não [...] aos aspectos sobre onde esse conhecimento foi originado - o 'como' da ciência" (DUSCHL apud McCOMAS; CLOUGH; ALMAZROA, 1998, p. 9). Isto é, há uma crítica ao ensino sobre os fatos da ciência em detrimento do ensino sobre os processos de construção da ciência. Essa crítica já estava presente em Matthews (1995), quando o autor exemplifica uma série de críticas ao ensino de ciências tradicional que levaram à inclusão de objetivos de conhecimento e conteúdos epistemológicos e meta-científicos nos documentos curriculares americanos dessa época, como o da AAAS e o Projeto 2061. Entretanto, raramente é mencionado nessas propostas os detalhes a respeito do contexto para o qual se propõe tal educação em ciências com viés epistemológico explícito.

Analisando as propostas, parece claro que os autores frequentemente se referem ou intentam à criação de parâmetros universais ou universalizáveis sobre o que se deve ensinar sobre a ciência nas escolas. A fonte do conhecimento é sempre um parâmetro externo, seja o consenso de especialistas (ALTERS, 1997; OSBORNE et al, 2003; LEDERMAN et al, 2002) um consenso baseado na análise de documentos curriculares (McCOMAS; OLSON, 1998), ou outros. Esse, sem dúvida, é um aspecto que aproxima o desenvolvimento desses textos curriculares à racionalidade tyleriana, tendo em vista que nessas racionalidades, a fonte (ou ao menos uma das fontes, no caso da proposta de Tyler) do conhecimento é o consenso de especialistas no tema. Além disso, o que se está a propor é a lógica do "melhor conhecimento possível" para a temática. Neste caso, embora haja a retórica como em Matthews (1995) de que ensinar sobre $\mathrm{NdC}$ permitiria o posicionamento crítico dos cidadãos frente às temáticas científicas, ao engessar a discussão sobre as ciências numa lista de características "que deveriam ser ensinadas" ou que "todos os estudantes deveriam saber" (OSBORNE et al, 2003), acaba-se por substituir conteúdos conceituais por conteúdos epistemológicos e metacientífcos, possibilitando que mais uma vez a capacidade crítica dos estudantes fique eclipsada por conteúdos que "devem ser ensinados". 
Esta observação endossa o argumento de Lopes (2015a; 2015b) e Macedo (2017) no debate sobre normatividade. Analisando essa trajetória específica de formação de um consenso sobre "o que deve ser ensinado" a respeito de $\mathrm{NdC}$, é possível observar que estes conhecimentos da lista consensual, que já foram hegemônicos no debate sobre introdução da epistemologia na escola básica, nem sempre estiveram lá. E, mais do que isso, a demanda de inclusão não parece ter surgido da percepção de que esses conhecimentos eram/são conhecimentos poderosos fundamentais para acesso a posições de poder na sociedade. Eles foram colocados lá por formuladores acadêmicos de políticas públicas. Analisando as publicações, não é possível encontrar um compromisso explícito desses formuladores a respeito de uma educação que visa transformar realidades, porque sequer as realidades a que se destinam essas formulações são discutidas. A discussão centra-se em torno da problemática do conhecimento, ao que Alsop e Gardner (2017) chamam de uma espécie de reedição do debate demarcacionista na filosofia das ciências.

Outro ponto de contato entre a lista consensual e a racionalidade tyleriana materializa-se por meio da concepção de avaliação que está por trás da primeira. Por intermédio de instrumentos que buscam analisar em que grau os objetivos foram atingidos, o objetivo da avaliação é "fornecer informações sobre a eficácia das experiências de aprendizagem na modificação do comportamento dos alunos" (LOPES; MACEDO, 2011: p. 49). Esta também é a busca de muitos trabalhos dentro da perspectiva da VC, ao relatar a criação de experiências educacionais que, ao final, lançam mão de questionários preparados previamente (VNOS, p. ex.) para avaliar a eficácia do processo em mudar concepções dos estudantes. Uma vez que estes questionários são definidos previamente, mais uma vez há o desprezo do contexto em que essas experiências educativas são levadas a cabo e há o reforço da preocupação em padronizar os resultados de diferentes realidades. Como seria possível ao estudante analisar o próprio contexto, que é sempre local, com uma lista de características gerais e pretensamente universais sobre a ciência? Todos os aspectos levantados pela lista são importantes em todos os contextos? Há aspectos que não estão na lista e deveriam ser considerados em algum contexto específico? Ser um cidadão crítico significa saber mais sobre determinados itens da lista do que de outros ou simplesmente significa saber mais sobre os itens da lista?

Estas avaliações propostas pelos formuladores da lista consensual flertam significativamente com a cultura da testagem analisada por Miller (2014). Outros pesquisadores, vão além e admitem que é importante manter atenção na constituição dos perfis conceituais, uma vez que muitas das concepções contidas na lista consensual já são conhecidas dos estudantes na forma de concepções alternativas e, por isso, o trabalho docente seria engajar-se no ensino para a mudança conceitual (CLOUGH, 2006). Nessa perspectiva, observamos em um exemplo prático como a centralidade do conhecimento e a definição sobre o que deve ser ensinado como um paradigma para todos os contextos e situações escolares vitima não só os conteúdos conceituais, como também a discussão epistemológica sobre a ciência, que deveria ter em seu cerne a contextualização, capaz de evitar o perigo de tornar-se apenas novos conteúdos, como alertou Matthews (2012). Por esse motivo, a lista consensual deve ser repensada na medida em que não há 
acordo desses parâmetros que aqui analisamos com as premissas básicas de onde supostamente derivariam (formação de cidadãos críticos etc.).

\section{Ciência integral}

A proposta do autor americano Douglas Allchin (2011c) parte de uma crítica à VC, abordada anteriormente, especialmente ao fato de este modelo avaliativo para $\mathrm{NdC}$ se basear em conteúdo declarativo sobre a ciência. Retomando críticas endereçadas à lista consensual, Allchin (2011c) afirma que o conhecimento sobre a ciência precisa ser funcional e não declarativo. Para o autor, a utilização de uma lista de asserções sobre a ciência teria como consequência a memorização e um possível entendimento sobre a ciência e não necessariamente a aplicação desse conhecimento, isto é, a VC não capacitaria os estudantes a analisar e avaliar situações reais, para as quais os conhecimentos sobre ciência deveriam ser requisitados. Outro aspecto que Allchin (2011c, 2012) chama a atenção é a inapropriação de uma prática que se tornou comum a partir da lista consensual, qual seja: a utilização de casos e episódios (históricos ou não) que ilustram um ou alguns itens da lista consensual sobre ciência (e.g. McCOMAS, 2008). Para o autor, esta atitude pode levar a uma visão parcial do que é a ciência, na medida que apenas alguns aspectos serão abordados e não outros. Para superar essa característica, Allchin (2011c) propõe a utilização de casos autênticos, sejam históricos ou contemporâneos, em que haveria uma abrangência maior a respeito dos diversos aspectos que compõem a prática científica. Com base nisso, propõe o seu modelo, que nomeia como "ciência integral", justamente por entender que a "ciência integral, como a comida integral, não exclui ingredientes essenciais e possibilita um entendimento [sobre ciência] mais saudável" (ALLCHIN, 2011c, p. 524)

Allchin (2011c), então, apresenta uma lista de aspectos (que ele ressalta não serem exaustivos) referentes à confiabilidade da informação científica, sintetizados em uma lista. Esses aspectos fazem referência aos protótipos construídos pelo autor, denominado KNOWS para avaliar o conhecimento de estudantes a respeito de $\mathrm{NdC}$, como o caso da periodicidade do exame de mamografia em mulheres acima de 40 anos, da relação entre vacinas e autismo, entre outros. Esses protótipos constituem-se em casos extraídos, em geral, da mídia tradicional, com fonte para diversos recursos, nos quais os estudantes podem se informar para construir um argumento. Como Allchin (2011b) aponta, a avaliação sobre o que os estudantes aprenderam deve ser feita em relação à robustez das evidências que eles levam em consideração ao construir sua resposta ao problema proposto no protótipo, em vez do alinhamento a determinadas afirmações que porventura caracterizem a ciência. $\mathrm{O}$ autor propõe ainda, em termos gerais, que a avaliação ocorra sob três critérios: organização/unicidade do argumento em torno de uma ideia central; abrangência, isso é, sua completude, a capacidade de relacionar ideias diferentes; e profundidade, a capacidade de transmitir ideias de forma convincente, usando exemplos.

A primeira observação importante sobre o modelo proposto por Allchin (2011c) é a sua ênfase na avaliação. Assim como o instrumento de Lederman, a motivação principal de Allchin ao propor seu modelo é avaliar o conhecimento de estudantes sobre a ciência. Diferente de Lederman, essa avaliação não se dá a 
partir de uma métrica de comparação com um conhecimento declarativo sobre a ciência (os tenets), mas de toda forma, ao fazer essa escolha, Allchin opta por enfatizar uma dimensão da educação - qual seja, a da avaliação - em detrimento de outras dimensões. O autor assume como dado o fato de que os professores "inevitavelmente ensinam para o teste" (ALLCHIN, 2011c, p. 519) ou que "em nossa nova era do 'accountability', pelo menos, os testes não irão embora tão cedo" (ALLCHIN, 2011b, p. 193). A partir disso, endossa: "O que poderia ser, então, considerado um bom teste para habilidades de NdC?" (ALLCHIN, 2011c, p. 519). Ou ainda mais enfaticamente: "Por que os professores não deveriam ensinar para o teste?" (ALLCHIN, 2011b, p. 193). Os testes são elaborados com base em uma matriz de referência, que no caso de Lederman mede a distância das respostas dos estudantes ao que se considera o consenso de experts no conhecimento sobre a ciência, e no caso de Allchin aposta na medida da robustez das evidências mobilizadas pelos estudantes quando estes avaliam uma controvérsia científica. Considerando isso, independentemente do julgamento que se faça a respeito de um ou outro modelo (como mais ou menos apropriado para o tipo de educação em ciências que desejamos), é certo que tanto um modelo quanto o outro, com sua ênfase em processos avaliativos - isto é, o estreitamento da relação entre currículo e avaliação -, aproximam-se de registros tylerianos, do ponto de vista curricular. No caso de Allchin (2011c), a pedra angular da alfabetização científica/letramento científico é tomada como objetivo para todos os contextos educacionais, sem maiores questionamentos, o que Alsop e Gardner (2017) já haviam apontado como algo recorrentemente presente na literatura em ensino de ciências e que deixa de fora um debate importante sobre o que significa ser considerado "letrado" ou "iletrado" em algo (CORBETT, 2008).

Ainda que avaliemos a proposição de Allchin como aparentemente menos normativa que a de Lederman, há, ainda, nos dois casos, um ponto de fuga para o qual convergem os esforços da pesquisa, isto é, um objetivo final de formação que não é posto em questão. Conforme o curriculista Gert Biesta (2007), a pesquisa educacional, a partir de uma retórica que valoriza a adoção de práticas educativas baseadas em evidências oriundas da pesquisa, tem dividido a ação educativa entre fins e meios. Nessa divisão, os fins da educação têm sido assumidos como "dados", enquanto os meios constituiriam aquilo para que verdadeiramente a pesquisa deveria se voltar. Esta perspectiva constitui um modelo tecnicista a respeito do para o quê serve a pesquisa educacional e a própria educação em si (BIESTA, 2007). É importante notar que Allchin (2011c) chega a postular um princípio fundacional da educação em ciências como sendo promover nos estudantes a capacidade de "entender como a ciência funciona com o objetivo de interpretar a confiabilidade das afirmações científicas nas tomadas de decisão públicas e pessoais” (p. 521). Como princípio fundacional, ele não é posto em questão, tornando-se uma espécie de axioma que justificará o desenvolvimento de meios (os instrumentos de avaliação) para atingir esse fim. Note-se que esse argumento não significa que toda pesquisa deve debruçar-se de forma profunda sobre ambas as questões (os fins e os meios), mas a afirmação de Allchin a respeito dos fins da educação em ciência não possui uma característica situada e contingente, mas sim totalizante e normativa. $\mathrm{O}$ autor não aborda, por exemplo, se este axioma seria válido para escolas urbanas 
ou rurais, escolas estadunidenses ou quaisquer escolas ao redor do mundo etc. Ao mesmo tempo, ao não pontuar essas características situadas - e, portanto, não problematizar seu próprio axioma -, ocorre a desconexão entre fins e meios, na medida que o importante, na pesquisa em tela, passa a ser o desenvolvimento de um instrumento avaliativo otimizado para esse postulado estabelecido por ele como objetivo da educação em ciências em todo tempo e espaço.

Ainda relacionado a esse objetivo estabelecido por Allchin, pode-se questionar se a tomada de decisões pessoais é algo relevante para uma educação em ciências democrática, conforme discussão estabelecida por Rudolph e Horibe (2016). Ou ainda, em que medida a tomada de decisões está ao alcance de todos os cidadãos. Pode-se questionar, ainda, em que medida uma educação em ciências focada em decisões envolvendo temas científicos em contextos pessoais pode reforçar um ideário neoliberal na Educação em Ciências (PINHÃO; MARTINS, 2016). Colocando de outra forma, é possível afirmar que mesmo se o estudante souber avaliar um caso profundamente como Allchin propõe, isso de pouco valerá se houver ainda um fosso entre a população e os espaços de decisão sobre políticas públicas envolvendo temas científicos. Por isso, é fundamental explorar com os estudantes as contingências estruturais da sociedade que estão envolvidas e de que forma o discurso científico (ou discursos que se pretendem científicos) se envolve na construção desse déficit democrático.

Allchin (2011c) afirma que o conhecimento sobre a ciência deve ser contextualizado, o que o motiva a construir seus protótipos usando notícias reais para avaliar o conhecimento dos estudantes sobre NdC. Entretanto, entendemos ser importante pensar a contextualização de maneira mais ampla. Barton (1998) afirma que nos movimentos de contextualização do conhecimento a relação do conhecimento com os estudantes é pensada como uma via de mão única, em que algo é construído a priori para ser ensinado aos estudantes, deixando de levar em consideração o contexto em que o conhecedor e o conhecido (os estudantes e o conhecimento) se relacionam. Costa e Lopes (2018), na mesma direção, entendem que a contextualização em geral torna-se uma tentativa de expulsão da diferença de dentro do currículo, daquilo que pode fugir ao controle, buscando prever ao máximo o que deve ser abordado, inclusive definindo quais devem ser os elementos de contextualização para cada situação. Com isso, adiciona-se ao currículo estes elementos de contextualização e, depois, busca-se entregar uma experiência pronta, estreitando a possibilidade de construção curricular de acordo com cada realidade.

O que parece um preciosismo, já que existe uma multiplicidade de casos propostos e algum caso há de se adequar a cada realidade, na verdade é uma questão mais profunda que envolve a disputa do sentido de contextualização. Como palavra polissêmica, o termo "contexto" alude a diferentes sentidos a depender do campo em que circula. Se tomamos, por exemplo, o sentido de contexto na historiografia, este diz respeito ao entendimento da história dos conhecimentos e práticas históricas devidamente ligados aos espaços em que circulou, ao ambiente cultural da época e aos acontecimentos mais amplos do ponto de vista histórico. Matthews (1995), ao propor a aproximação entre História e Ensino de Ciência, tinha a intenção de superar um ensino de ciências abstrato, cuja atenção não 
fosse destinada apenas aos produtos da ciência, mas também à história de sua construção, e às bases sociais e epistemológicas que a sustentam. Além disso, o discurso sobre a necessidade de contextualização tem sido reverberado como um esforço necessário para humanizar a educação em ciências (AIKENHEAD, 2009) e promover o entendimento dos estudantes sobre as relações entre ciência e sociedade, bem como aproximar as ciências de seus próprios contextos sociais, buscando uma identificação cultural entre os estudantes e a ciência que lhes é ensinada (idem). São, portanto, diversos sentidos para contextualização do conhecimento que precisam ser entendidos segundo os seus deslizamentos de significados. Podemos localizar estes diferentes (e que interseccionam entre si) tipos de contextualização como habitando um entre-lugar de dois polos virtuais ${ }^{8}$ entre a normatividade absoluta, em que todas as ações pedagógicas seriam prescritas, e a deliberação circunstancial absoluta, onde tudo estaria em aberto para deliberação dos atores sociais envolvidos com o ato educativo em cada circunstância. Quando a contextualização se aproxima da normatividade absoluta, podemos dizer que ela assume um papel de fixar o conhecimento como um objeto, uma coisa (cf. LOPES, 2015a) que deve ser transmitida/apreendida. No caso dos protótipos de Allchin (2011c), entendemos que estes se aproximam do polo normativo na medida que definem temas de interesse e elementos de contextualização prévios à prática de sala de aula e focam na avaliação e em como estão os estudantes preparados para a tomada de decisões de assuntos científicos. Allchin aponta que estes casos extraídos de eventos atuais seriam encontrados pelo "cidadão típico" (idem, p. 519) na mídia em geral. Cabe questionar aqui a respeito de que cidadão típico estamos tratando. Um homem do campo ou um indígena brasileiro, por exemplo, cabem dentro desta categoria "cidadão típico" de Allchin?

Entendemos que é a aproximação com a deliberação circunstancial que poderá produzir uma contextualização mais eficaz no ensino de ciências. Não há como prever antecipadamente muito a respeito dos contextos dos estudantes que estarão em sala de aula em um determinado espaço-tempo. Como Paulo Freire dizia, a leitura do mundo precede a leitura da palavra, por isso o exercício de contextualização deve prover, análogo à pesquisa vocabular de Freire, contextos "grávidos de mundo", a partir da leitura de mundo dos grupos com os quais se trabalha (KLEIN, 2017). É tentador pensar que ao advogar por uma educação em ciências que se volte para cada contexto particular estamos negando a possibilidade de que o estudante conheça para além do seu próprio contexto local, isso é, das questões mais amplas da sociedade. Esse pensamento dicotômico em que o local nega o global ou vice-versa é uma invenção de uma racionalidade ocidental, que cria oposições e hierarquiza conhecimentos, civilizações (SANTOS, 2010). Nesse sentido, buscar a convergência entre o local e o global, entendidos não como opostos, mas como extensões um do outro, pode ser um caminho frutífero para promover discussões sobre ciência potencialmente mais relevantes aos diferentes conjuntos de estudantes. Por exemplo, o agronegócio afeta de formas diferentes as comunidades rurais produtoras de alimentos e as urbanas. O aquecimento global afeta de maneiras diferentes o Sul Global e o Norte Global. Mesmo uma tragédia como uma enchente - considerando que seja ela um efeito das mudanças climáticas - possui efeitos, valores e significados diferentes, ocorra ela na zona sul da capital 
do Rio de Janeiro ou na Baixada Fluminense. Por esse motivo, a contextualização radical, conforme defendida por Lopes (2015a), é uma alternativa que nos empurra em direção ao polo de deliberação circunstancial capaz de ampliar a perspectiva democrática do currículo (LOPES, 2012).

Esse argumento não significa a impossibilidade de proposição de protótipos, como faz Allchin (2011c), mas a necessidade de sempre apresentar sua contingência. Tornar transparente o destinatário suposto dos textos produzidos, isto é, esclarecer o contexto do qual e para qual se fala, pode dificultar sua captura pelos mecanismos de normatização curricular, pelo accountability e pela cultura da testagem (cf. MILLER, 2014; BIESTA, 2012), cada vez mais presentes na educação. É importante também sublinhar a condição de entre-lugar da contextualização. Um exemplo em que se enxerga isso com mais clareza é a contextualização histórica. Esta sempre estará presa a fatos do passado ligados a determinado evento que se deseja estudar na escola, o que, a princípio, moveria esse tipo de contextualização para um polo mais normativo. Isso nos leva a crer que a deliberação circunstancial/contextualização radical tem limites impostos pelo próprio conhecimento sobre o qual se trata, o que pode ser entendido como um ponto de tensão no ensino de ciências.

\section{Abordagem por semelhança de famílias}

O terceiro modelo de $\mathrm{NdC}$ a ser abordado possui sua origem, assim como a ciência integral, em 2011, com as críticas dos filósofos Gürol Irzik e Robert Nola ao modelo VC. Diferente do modelo de Allchin (2011c) que gerou um intenso debate (ver SCHWARTZ et al, 2012 e ALLCHIN, 2012) sobre a própria validade do modelo que este propõe, as críticas tecidas por Irzik e Nola $(2011 ; 2014)$ geraram pouca controvérsia na forma de artigos-resposta no meio acadêmico embora, como Allchin, tenham alcançado alguma expressão.

O conjunto de críticas de Irzik e Nola (2011) aos princípios da lista consensual (tenets) de Lederman em alguns pontos vai por caminhos parecidos com os das críticas de Allchin (2011c). Porém, Irzik e Nola destacam a incoerência existente entre algumas das afirmações que compõem a lista consensual e a divisão entre conhecimento científico e práticas de investigação científica, afirmando que essa divisão é artificial e exclui uma parte importante do que consideramos ser a ciência. Além disso, afirmam que a caracterização da ciência proposta pela lista consensual peca por ser uma visão excessivamente monolítica e estreita do empreendimento científico, e por desconsiderar as diferenças significativas existentes entre determinadas disciplinas científicas e mesmo entre tradições disciplinares dentro de uma mesma ciência. Feitas estas críticas, os autores intentam propor uma "visão que não tenha as limitações e fragilidades da visão consensual" (IRZIK; NOLA, 2011, p. 593). Buscam, portanto, fixar uma nova imagem para o empreendimento científico que represente melhor a realidade da ciência do que a lista consensual. Apresentamos a seguir, os principais aspectos do modelo proposto pelos filósofos.

O principal argumento de Irzik e Nola (2011) é de que o empreendimento científico é muito mais plural do que a lista consensual consegue representar. Por esse motivo, usam a ideia de semelhança de famílias do filósofo Ludwig Wittgenstein 
para construir a abordagem que ficou conhecida ulteriormente por FRA to NOS, na tradução, Abordagem por Semelhança de Famílias para NdC. Essa abordagem, segundo os autores, proporcionaria uma compreensão mais próxima do que se faz nas diversas ciências. Começando por apresentar as principais características do pensamento de Wittgenstein, Irzik e Nola chegam à aplicação deste pensamento à descrição da ciência, baseada não no que todas as ciências têm em comum, mas em suas similaridades e diferenças. No artigo de 2011 (IRZIK; NOLA, 2011), os autores propõem 4 categorias a partir das quais as diferentes disciplinas científicas poderiam ser agrupadas. São elas: (1) atividades, (2) objetivos e valores; (3) metodologias e regras metodológicas; (4) produtos. Para exemplificar, os autores destacam que a astronomia é uma ciência na qual atividades de observação são importantes, ao passo que paleontólogos usam mais a capacidade de reconhecer e classificar fósseis no meio de sedimentos e não utilizam a observação da forma que os astrônomos fazem. Em compensação, botânicos performariam atividades de reconhecimento e classificação, o que os colocaria num grupo de semelhança junto dos paleontólogos, mas longe dos astrônomos, por exemplo.

Irzik e Nola publicam, em 2011, o artigo fundacional da Semelhança de Família num periódico de educação em ciências. Ainda que os autores sejam filósofos, o público ao que o trabalho se destina, considerando a missão do periódico, gera uma expectativa de que questões educacionais, praticamente não consideradas pelos autores, sejam orientadoras da construção da proposta. Diferente de Allchin (2011c), que postula um objetivo geral para a educação em ciências - analisado anteriormente -, não é possível notar no modelo dos filósofos qualquer menção a um ideal ou perspectiva educacional que norteie a construção da proposta. As considerações educacionais foram acrescentadas (tanto no artigo de 2011 como no de 2014) após a discussão filosófica, à guisa de sugestão de aplicações na sala de aula. Esta ausência/presença, se analisada a partir das considerações da teoria curricular, reforçam dois aspectos. O primeiro, novamente, refere-se ao caráter normativo da proposta. Conforme ressaltamos no início da seção, o objetivo dos autores é criar uma imagem de ciência mais fidedigna que a VC, com o objetivo de transpor esse conhecimento "verdadeiro" sobre a ciência a qualquer contexto de ensino, incorrendo assim como os demais modelos na perspectiva da via de mão única para a produção e utilização dos conhecimentos de NdC. Outro aspecto é o viés de produção do modelo de $\mathrm{NdC}$ a partir do "melhor conhecimento" decidido por especialistas, o que, juntamente com o caráter mais normativo coloca esse modelo de $\mathrm{NdC}$ próximo das perspectivas tylerianas e bobbitianas de currículo.

Ademais, conforme notado por Alsop e Gardner (2017), ao insistir na demarcação e no traçar de fronteiras para delimitar o conhecimento científico, Irzik \& Nola $(2011$; 2014) vão contra um princípio-chave de Wittgenstein, que seria perceber as diferentes disciplinas científicas e mesmo a ciência e a nãociência, ou a ciência e demais disciplinas não-científicas (história, literatura) desde um ponto de vista relacional em vez de demarcatório. A formulação de algumas questões pelos autores passíveis de serem usadas em sala de aula, a partir de uma abordagem seguindo o modelo da semelhança de famílias apresenta problemas parecidos com os que Allchin (2011c) levanta em relação à lista consensual, isto é, o alto grau de abstração de algumas proposições de tais modelos. No caso da 
abordagem por semelhança de famílias, tais proposições aparecem na forma de questões que podem ser direcionadas em sala de aula, por exemplo "qual o objetivo de fazer um experimento e como isso se relaciona com a teoria?" (IRZIK; NOLA, 2011, p. 603) ou ainda “como a observação se diferencia da experimentação?”, que muito se assemelham às questões do VNOS-C, analisado por Allchin (2011c). Um elemento que está presente nos outros dois modelos, mas não aparece no modelo de Irzik e Nola, é um protocolo voltado à avaliação, como as várias versões do VNOS, no caso da VC, e o modelo KNOWS, proposto por Allchin. Entretanto, conforme apontamos, olhado à luz da teoria de currículo, há mais elementos que aproximam esse modelo dos demais do que o afasta, especialmente no que diz respeito a seu caráter normativo.

\section{CONSIDERAC̦ÕES FINAIS}

O primeiro aspecto a considerar é que a análise curricular que empreendemos, buscando fazer inferências a respeito de fragmentos de teorias curriculares a que determinados registros se aproximam ou se afastam e quais as consequências disso para o campo do ensino sobre as ciências, revela alguns aspectos importantes desses "modelos" de NdC. A constatação do afastamento do questionamento sobre os fins do ensino sobre as ciências, conforme nossa análise, ressalta a importância de nos reconectarmos com a questão a respeito do "por quê" ensinar ciências (MOURA, 2019). Deveríamos nos engajar em um exercício permanente de pensar "Que condições aqui e agora são importantes para pensar a educação sobre as ciências? Que novos formatos, que novas possibilidades podem ser exploradas nesse contexto?".

Hoje, por exemplo, vivemos o dilema da pós-verdade na sociedade e na Educação em Ciências, além da questão de o modelo de democracia na sociedade começar a dar sinais de desgaste e esgarçamento. Que tipo de discussões sobre a ciência podemos produzir em um contexto como esse? Nesse contexto, a necessidade de definir exatamente onde termina a "Ciência" e onde começa a pseudociência talvez não seja tão urgente quanto saber identificar quando um discurso se utiliza de uma roupagem científica para validar sua autoridade. Afinal, sabemos com clareza (estudantes e professores) o que constrói a autoridade da ciência ou sabemos apenas que ela é sinônimo de autoridade?

Podemos entender que Allchin (2011a; 2011b; 2011c; 2012) ao criticar um estudo de características das ciências e propor um estudo mais integral sobre as ciências, de modo a permitir aos estudantes se posicionarem sobre assuntos científicos, caminha por trilhas parecidas. Porém entendemos que a proposta de Allchin (2011a; 2011b; 2011c; 2012) se torna problemática, devido à sua aderência a um caminho prescritivo-normativo sobre como se deveria abordar $\mathrm{NdC}$ em seus diversos contextos, conforme apontamos acima. Estamos nos opondo aqui à norma não por conta de alguma falha epistemológica ou ontológica que jogue contra a existência dessa norma. Isso significa que a normatividade não é, em nossa opinião, ruim per se (se pudéssemos separar essa dimensão ontológica da dimensão prática). Mas o que a torna problemática nesse caso é a sua tendência em ser "capturada" pelos mecanismos do accountability na educação e transformada em 
algo que impediria a reflexão crítica sobre a ciência. Quando o conteúdo histórico e epistemológico da ciência se transforma em mais um conteúdo escolar a ser avaliado, a constar nos exames etc., ele perde a sua potência, pois logo torna-se uma preocupação a necessidade de que os estudantes tenham um conhecimento metrificável sobre como se constrói a ciência. Dentro dessa perspectiva, por exemplo, a possibilidade de um aluno sair da escola sem definições sobre a diferença entre leis e teorias, ou sobre o papel dos experimentos em cada ciência se tornaria temerária. Como consequência desse temor, perde-se a medida de como a ciência afeta a vida de cada grupo particular de estudantes, conforme Barton (1998) alerta. Será que estudar sobre as ciências significa que um estudante da periferia do Crato, interior do Ceará, deve saber sobre as mesmas coisas que um estudante de um bairro nobre de São Paulo? Para tornar a questão menos geográfica: será que um estudante da Rocinha, a maior favela do Brasil, localizada no bairro de São Conrado, Rio de Janeiro, é afetado pela ciência de forma igual a um estudante de um condomínio de luxo, localizado no mesmo bairro de São Conrado? Isso não significa dizer que um deve estudar sobre a ciência e outro possui questões mais urgentes a lidar e por isso precisa de "outra educação", o que poderia ser confundido com um discurso contencionista das classes populares. Ambos devem estudar sobre as características da ciência porque, seja de uma forma ou de outra, a ciência afeta suas vidas. Porém, quando entra em cena a norma, o conhecimento metrificável, fatalmente deixamos de apostar em uma educação sobre ciências que signifique algo para o estudante pobre e também para o rico. A discussão passa a ser, para ambos, sobre algo que será testado ao final, recaindo novamente na questão da cultura da testagem, conforme Miller (2014).

Advogamos, portanto, uma concepção que dê espaço para explorar a ciência e sua construção de formas diferentes conforme cada contexto. Afinal, a demanda do estudo sobre ciências já está nos documentos curriculares existentes atualmente, sendo assim, qual a vantagem de fixar uma norma? Essa norma garantirá a "aprendizagem" sobre $\mathrm{NdC}$ ?

Observe-se aqui que a crítica não é dirigida aos pesquisadores em Educação em Ciências por produzirem listas consensuais sobre NdC. Esse tipo de interpretação heurística do conhecimento que procura agrupar, sintetizar, comparar e simplificar conceitos difíceis é algo comum não só na área de Educação em Ciências como em qualquer área do conhecimento. Allchin (2011c) toma o mesmo rumo ao dizer que suas dimensões de confiabilidade não são exaustivas. A crítica, se endereça, nesse ponto, à tentativa de estabilizar, por meio de documentos curriculares, tal visão sobre os aspectos metacientíficos na Educação em Ciências. Sendo assim, listas, consensos e sínteses podem ter um papel muito importante para discussão na formação de docentes para lidar com aspectos de $\mathrm{NdC}$ em sala de aula, se apropriados de forma crítica pelos futuros docentes, de forma que problematizem o porquê ensinar ciências e a que destinatários supostos encaminham-se as diferentes propostas.

A formação do professor é um ponto fundamental, pra completar o argumento aqui exposto. Defendemos que não é desejável que listas de consenso sobre as características da construção da ciência sirvam de modelo para construção curricular nem como prescrição para o trabalho de sala de aula da educação básica. 
Pode-se questionar, então, como seria desejável o ensino sobre as ciências na escola. Sem a pretensão de esgotar o assunto, entendemos que a premissa fundamental para nossa defesa é que o professor seja entendido como um intelectual crítico (CONTRERAS, 1997). Nesse sentido, o professor deveria estar continuamente nutrindo-se do debate acadêmico (e contribuindo a esse debate) sobre as formas de abordar $\mathrm{NdC}$ para então decidir o caminho mais oportuno em cada caso. O leitor não deve entender que culpamos o professor caso o ensino sobre ciências nas escolas não esteja funcionando a contento, mas sim que nos somamos aqui às diversas vozes presentes na literatura educacional que chamam atenção para a necessidade de que as políticas públicas para educação garantam não só as condições de trabalho ao professor - como plano de carreira, tempo adequado para atuar em ensino e pesquisa, condições estruturais nas escolas - mas, também, a liberdade para que o professor possa decidir o melhor para cada contexto de cada turma a que leciona. Ou seja, além de uma formação epistemológica sólida (da qual esses debates sobre $\mathrm{NdC}$ no ensino de ciências seriam apenas uma parte), há que se garantir autonomia para ensinar, conforme a pesquisa em políticas educacionais tem enfatizado. A coesão das tradições disciplinares seria garantida, conforme o argumento de Lopes (2015a), pelos diversos outros elementos que constituem a realidade educacional, como o processo de formação inicial, livros didáticos, os próprios documentos curriculares já existentes, entre outros aspectos.

Os modelos de $\mathrm{NdC}$, conforme nossa análise, atuam na tentativa de normatizar ainda mais o ambiente educacional (através de testes padronizados e/ou por meio de traços que remetem a perspectivas tecnocráticas de currículo) e, assim, constrangem o surgimento da diferença na sala de aula e, portanto, a possibilidade de formação de estudantes a partir de uma conexão real da ciência que é ensinada com seus próprios contextos (BARTON, 1998).

Os modelos analisados silenciam sobre a pluralidade das ciências (ALSOP; FAWCETT', 2010) já há muito advogada na literatura dos Science Studies, e insistem na proposição de testes padronizados e na fixação de determinado modelo civilizatório, o "cidadão comum", isso quando é mencionado. Neste caminho, há o apagamento da possibilidade da diferença no currículo, ou ainda, a redução da discussão do conhecimento científico ao caráter demarcatório definido por especialistas. E, assim, admite-se um currículo que atua em uma via de mão única, como se nas escolas não se produzisse conhecimento, mas apenas se transmitisse um conhecimento prescrito de antemão (LOPES, 2015a). Não se trata de adaptar novos modelos de $\mathrm{NdC}$, mas sim de pensar sem esses modelos. Trata-se de investir em professores epistemologicamente e politicamente empoderados que possam inventar caminhos para a formação epistemológica e política dos estudantes. Também relacionado a isso, sublinhamos a necessidade de refletir continuamente sobre o porquê de ensinar (sobre) ciências em cada contexto educacional (MOURA, 2019), o que pode servir como um farol orientador da prática de sala de aula de cada docente. 


\section{AGRADECIMENTO}

$\mathrm{O}$ autor e as autoras agradecem ao CNPq pelo financiamento de suas pesquisas.

\section{REFERÊNCIAS}

ABD-EL-KHALICK, F; LEDERMAN, N. G. The influence of history of science courses on students' views of nature of science. Journal of Research in Science Teaching, v. 37, n. 10, p. 1057-1095, 2000.

AIKENHEAD, G. S. Educação científica para todos. Mangualde: Edições Pedago, 2009.

ALLCHIN, D. Evaluating knowledge of the nature of (whole) science. Science Education, v. 95, n. 3, p. 518-542, 2011c.

ALLCHIN, D. Nature of Science in an Age of Accountability. The American Biology Teacher, v. 73 , n. 3, p. 193-195, 2011 b.

ALLCHIN, D. Teaching whole science. The American Biology Teacher, v. 73, n. 1, p. 53-55, 2011 a.

ALLCHIN, D. Toward clarity on whole science and KNOWS. Science Education, v. 96, n. 4, p. 693-700, 2012.

ALSOP, S.; FAWCETT, L. After this nothing happened. Cultural Studies of Science Education, v. 5, n. 4, p. 1027-1045, 2010.

ALSOP, S.; GARDNER, S. Opening the black box of NOS: Or knowing how to go on with science education, Wittgenstein, and STS in a precarious world. Canadian Journal of Science, Mathematics and Technology Education, v. 17, n. 1, p. 27-36, 2017.

ALTERS, B. J. Nature of science: a diversity or uniformity of ideas? Journal of Research in Science Teaching, v. 34, n. 10, p. 1105-1108, 1997b.

ALTERS, B. J. Whose nature of science? Journal of Research in Science Teaching, v. 34, n. 1, p. 39-55, 1997a.

AMADOR-RODRÍGUEZ, R. Y.; ADURIZ-BRAVO, A. Concepciones emergentes de naturaleza de la ciencia (NOS) para la didáctica de las ciencias. Enseñanza de las Ciencias, n. Extra, p. 34993504, 2017.

BARTON, A. C. Reframing "science for all" through the politics of poverty. Educational Policy, v. 12 , n. 5 , p. 525-541, 1998.

BAZZUL, J. Science education as a site for biopolitical engagement and the reworking of subjectivities: Theoretical considerations and possibilities for research. In: Bencze, J. L.; Alsop, S. (ed.). Activist science and technology education. Springer Netherlands, p. 37-53, 2014.

BIESTA, G. Boa educação na era da mensuração. Cadernos de Pesquisa, v. 42, n. 147, p. 808-825, 2012.

BIESTA, G. Why "what works" won't work: Evidence-based practice and the democratic deficit in educational research. Educational theory, v. 57, n. 1, p. 1-22, 2007. 
CARTER, L. The elephant in the room: Science education, neoliberalism and resistance. In: Bencze, J. L.; Alsop, S. (ed.). Activist science and technology education. Netherlands: Springer, p. 23-36, 2014.

CLOUGH, M. P. Learners' responses to the demands of conceptual change: Considerations for effective nature of science instruction. Science \& Education, v. 15, n. 5, p. 463-494, 2006.

CORBETT, M. Captain Beefheart's piano: Confessions of an unrepentant illiterate. International Journal of Critical Pedagogy, v. 1, n. 2, p. 148-159, 2008.

COSTA, H. H. C.; LOPES, A. C. A contextualização do conhecimento no Ensino Médio: tentativas de controle do outro. Educação \& Sociedade, v. 39, n. 143, 2018.

DAGHER, Z. R.; ERDURAN, S. Reconceptualizing Nature of Science for Science Education. Springer Netherlands, 2014.

DAGHER, Z. R.; ERDURAN, S. Reconceptualizing the Nature of Science for Science Education. Science \& Education, v. 25, n. 1, p. 147-164, 2016.

EL-HANI, C.; TAVARES, E. J. M.; ROCHA, P. L. B. Concepções epistemológicas de estudantes de biologia e sua transformação por uma proposta explícita de ensino sobre História e Filosofia das Ciências. Investigações em Ensino de Ciências, v. 9, n. 3, p. 265-313, 2004.

HODSON, D; WONG, S. L. Going beyond the consensus view: Broadening and enriching the scope of NOS-oriented curricula. Canadian Journal of Science, Mathematics and Technology Education, v. 17, n. 1, p. 3-17, 2017.

IRZIK, G.; NOLA, R. A family resemblance approach to the nature of science for science education. Science \& Education, v. 20, n. 7-8, p. 591-607, 2011.

IRZIK, G.; NOLA, R. New directions for nature of science research. In: Matthews, M. R. (ed.) International handbook of research in history, philosophy and science teaching. Springer Netherlands, p. 999-1021, 2014.

KLEIN, R. Ler/Leitura. In: Streck, D. R.; Redin, E.; Zitkoski, J. J. (org.) Dicionário Paulo Freire. Belo Horizonte: Autêntica Editora, p. 240-241, 2017.

KLIEBARD, H. M. Os princípios de Tyler. Currículo sem Fronteiras, v. 11, n. 2, p. 23-35, 2011.

LARROSA, J. O ensaio e a escrita acadêmica. Educação \& Realidade, v. 28, n. 2, 2003.

LEDERMAN, N. G. et al. Views of nature of science questionnaire: Toward valid and meaningful assessment of learners' conceptions of nature of science. Journal of research in science teaching, v. 39, n. 6, p. 497-521, 2002.

LEDERMAN, N. G.; WADE, P.; BELL, R. L. Assessing understanding of the nature of science: A historical perspective. In: McComas, W. F. (org.) The nature of science in science education. Dordrecht: Kluwer, p. 335-350, 1998.

LOPES, A. C. Democracia nas políticas de currículo. Cadernos de Pesquisa, v. 42, p. 700-715, 2012.

LOPES, A. C. Normatividade e intervenção política: em defesa de um investimento radical. In: Alice Casimiro Lopes; Daniel de Mendonça. (org.). A Teoria do Discurso de Ernesto Laclau: ensaios críticos e entrevistas. São Paulo: Annablume, p. 117-147, 2015b.

LOPES, A. C. Por um currículo sem fundamentos. Linhas Críticas, v. 21, n. 45, 2015 a. 
LOPES, A. C.; BORGES, V. Currículo, Conhecimento e Interpretação. Currículo sem Fronteiras, v. 17 , n. 3, p. $555-573,2017$.

LOPES, A. C.; MACEDO, E. Teorias de currículo. São Paulo: Cortez, 2011.

MACEDO, E. Mas a escola não tem que ensinar? Conhecimento, reconhecimento e alteridade na teoria do currículo. Currículo sem Fronteiras, v. 17, n. 3, p. 539-554, 2017.

MARTINS, A. F. P. Natureza da Ciência no ensino de ciências: uma proposta baseada em "temas" e "questões”. Caderno Brasileiro de Ensino de Física, v. 32, n. 3, p. 703-737, 2015.

MATTHEWS, M. "História, filosofia e Ensino: a tendência atual de reaproximação." Caderno Brasileiro de Ensino de Física, v. 12, n. 3, p. 164-214, 1995.

MATTHEWS, M. R. Changing the focus: From nature of science (NOS) to features of science (FOS). In: Advances in nature of science research. Springer, Dordrecht, 2012. p. 3-26.

McCOMAS, W. F. (org.) The nature of science in science education. Dordrecht: Kluwer, 1998.

MCCOMAS, W. F. Seeking historical examples to illustrate key aspects of the nature of science. Science \& Education, v. 17, n. 2-3, p. 249-263, 2008.

McCOMAS, W. F.; CLOUGH, M. P.; ALMAZROA, H. The role and character of the nature of science in science education. In: McComas, W. F. (org.) The nature of science in science education. Dordrecht: Kluwer, p. 3-39, 1998.

MCCOMAS, W. F.; OLSON, J. K. The nature of science in international science education standards documents. In: McComas, W. F. (org.) The nature of science in science education. Dordrecht: Kluwer, p. 41-52, 1998.

MILLER, J. L. Teorização do currículo como antídoto contra/na cultura da testagem. Revista Científica e-Curriculum, v. 12, n. 3, p. 2043-2063, 2014.

MOREIRA, A. F. B. Currículo e gestão: propondo uma parceria. Ensaio: avaliação e políticas públicas em educação, v. 21, n. 80, p. 547-61, 2013.

MOURA, C. O ensino de ciências e a justiça social - questões para o debate. Caderno Brasileiro de Ensino de Física, v. 36, n. 1, p. 1-7, 2019

OSBORNE, J., COLLINS, S., RATCLIFFE, M., MILLAR, R., DUSCHL, R. What "ideas-aboutscience" should be taught in school science? A Delphi study of the expert community. Journal of research in science teaching, v. 40, n. 7, p. 692-720, 2003.

PACHECO, J A. Reconceptualização curricular: os caminhos de uma teoria curricular crítica. Perspectiva, v. 18, n. 33, p. 11-34, 2000.

PENA, E. B. F. Artigo e Ensaio Científicos: dois gêneros e uma só forma. Dissertação de Mestrado. Programa de Pós-Graduação em Estudos Lingüísticos, Faculdade de Letras, Universidade Federal de Minas Gerais, Belo Horizonte, Minas Gerais, Brasil. 116p. 2005.

PIMENTEL, Juan. ¿Qué es la historia cultural de la ciencia? Arbor, v. 186, n. 743, p. 417-424, 2010.

PINHÃO, F.; MARTINS, I. Cidadania e ensino de ciências: questões para o debate. Ensaio Pesquisa em Educação em Ciências, v. 18, n. 3, 2016.

POPKEWITZ, T. S. PISA: números, estandarización de la conducta y la alquimia de las materias escolares. 
Profesorado. Revista de currículum y formación de profesorado, v. 17, n. 2, p. 47-64, 2013.

ROCHA, M. N.; GURGEL, I. Descriptive Understandings of the Nature of Science: Examining the Consensual and Family Resemblance Approaches. Interchange, v. 48, n. 4, p. 403-429, 2017.

RUDOLPH, J. L.; HORIBE, S. What do we mean by science education for civic engagement? Journal of Research on Science Teaching, v. 53, n. 6, p. 805-820, 2016.

SANTOS, B. S. Para além do pensamento abissal: das linhas globais a uma ecologia de saberes. In: Santos, B. S.; Meneses M. (org.) Epistemologias do Sul. Coimbra: Almedina, p. 23-72, 2010.

SANTOS, M. Uso da História da Ciência para Favorecer a Compreensão de Estudantes do Ensino Médio sobre Ciência. Revista Brasileira de Pesquisa em Educação em Ciências, v. 18, n. 2, p. 641-668, 31 ago. 2018.

SCHWARTZ, R. S., LEDERMAN, N. G., \& ADB-EL-KHALICK, F.. A series of misrepresentations: A response to Allchin's whole approach to assessing nature of science understandings. Science Education, v. 96, p. $685-692,2012$.

SILVA, T. T. Dcumentos de Identidade: uma introdução às teorias de currículo. Editora Autêntica, 2015.

SMITH, M. U.; LEDERMAN, N. G.; BELL, R. L.; McCOMAS, W. F.; CLOUGH, M. F. How great is the disagreement about the nature of science: A response to Alters. Journal of Research in Science Teaching, v. 34, n. 10, p. 1101-1103, 1997.

YOUNG, M. Teoria do currículo: o que é e por que é importante. Cadernos de Pesquisa, v. 44, n. 151, p. 190-202, 2014.

\section{NOTAS}

1 Note-se que isto não significa dizer que Young, Moreira e demais teóricos da linha crítica se posicionem favoravelmente aos exames padronizados.

2 Até porque, conforme Lopes (2015a), não é este o objetivo dos curriculistas que se inscrevem na tradição pós-estrutural, já que entendem a própria significação do quem vem a ser currículo como um espaço de disputa política e não de representação da realidade.

3 O termo "tenets" (princípios, em português) é muito utilizado na literatura internacional para referir às afirmações da VC. Por tornar a identificação imediata ao que queremos nos referir, usaremos esse termo em inglês no texto.

4 O artigo de Alters (1997a) foi recebido com uma crítica do grupo de Lederman (Smith et al, 1997) e uma tréplica de Alters (1997b), o que sugere um debate acalorado.

5 Conforme Lederman et al (2002), os questionários VNOS foram concebidos para pesquisa de concepções de $\mathrm{NdC}$, no entanto, vêm sendo usados em situações de avaliação de aprendizagem, como parte do largo corpo de literatura que o cita pode constatar.

6 A cautela aqui ao dizer que as listas de características são "mais ou menos estáveis" ocorre pois, conforme comentado por Alters (1997a), em alguns casos como o do questionário de Aikenhead e colaboradores, esta lista não está definida explicitamente. 
A natureza da ciência pelas lentes do currículo: normatividade curricular, contextualização e os sentidos de ensinar sobre ciências

7 A VC recebeu diversas críticas de natureza educacional, filosófica, entre outras. Não é do escopo deste artigo passar por todas estas críticas, mas para uma discussão destas, sugerimos conferir em Dagher e Erduran (2016) ou Martins (2015).

8 Chamamos de polos virtuais por entender que não há nem normatividade absoluta nem a deliberação circunstancial absoluta. Estas são apenas categorias para facilitar a análise.

9 É digno de nota ainda o fato de os artigos de Irzik e Nola $(2011 ; 2014)$ terem contribuído para a gestação de outro modelo também amplamente citado nos últimos anos, de Zoubeida Dagher e Sibel Erduran (ver DAGHER \& ERDURAN, 2014), o qual não analisaremos aqui porque subverteria o escopo definido para análise do artigo.

Submetido em 08/10/2019

Aprovado em 27/03/2020

Contato:

Cristiano Barbosa de Moura

Programa de Pós-Graduação em Ciência, Tecnologia e Educação

Centro Federal de Educação Tecnológica Celso Suckow da Fonseca

Av. Maracanã, 229. Rio de Janeiro

CEP 20.271-110 - RJ - Brasil 